\title{
Temporal analysis of air pollutants in the most affected monsoon region
}

\author{
Omar Kairan, Nur Nasehah Zainudin, Nurul Hasya Mohd Hanafiah, Nur Emylia Arissa Mohd Jafri, \\ Fukayhah Fatiha@Suhami, Muhammad Firdaus Mustapha \\ Faculty of Computer and Mathematical Sciences, Universiti Teknologi MARA Cawangan Kelantan, Malaysia
}

\section{Article Info}

Article history:

Received Mar 20, 2021

Revised Jun 9, 2021

Accepted Jun 17, 2021

\section{Keywords:}

Air pollution

Carbon monoxide

Cluster analysis

Nitrogen dioxide

Ozone

Particulate matter 10

Sulphur dioxide

Temporal variation

\begin{abstract}
Air pollution has become an issue at all rates in the world. In Malaysia, there is a system is known as air quality index (API) used to indicate the overall air quality in the country where the air pollutants include or the new ambient air quality standard are sulphur dioxide (SO2), nitrogen dioxide (NO2), carbon monoxide $(\mathrm{CO})$, ozone $(\mathrm{O} 3)$ and particulate matter with size less than 10 (PM10). The concentration levels of the air pollutants were said to be affected by the monsoon changes. Therefore, this study is conducted to examine the existence of temporal variations of each air pollutant then identify the differences of each air pollutants concentration in temporal variations. This study uses secondary data where data that has been retrieved from the Department of Environment (DOE) where it is data of air pollution specifically for Kota Bharu, kelantan records. Hierarchical agglomerative cluster analysis was conducted to group monthly air quality. As a conclusion, the study can conclude that the five air pollutants grouped into several different monthly clusters mostly representing the two main monsoon seasons. Mostly air pollutant varied accordingly towards the monsoon season. During the southwestern monsoon, air pollutant concentration tends to higher compare to the northeastern monsoon with mostly due to meteorological factors.
\end{abstract}

This is an open access article under the CC BY-SA license.

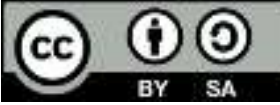

\section{Corresponding Author:}

Omar Kairan

Department Statistics

Universiti Teknologi Mara Kota Bharu City Campus

Lembah Sireh, 15050 Kota Bharu, Kelantan

Email: omarkr@uitm.edu.my

\section{INTRODUCTION}

Air pollution has turned our lives into a bane. Not only in our country, it involves countries all over the world. This is a problem. Simpler speaking, at all rates worldwide air pollution is a problem. For example, a high level of air pollutants can cause health problems in the environment, including respiratory conditions, conjunctivitis and lung functions.

In general, there are many studies have been done related to the temporal variation of pollution. There are five major pollutants listed by the Department of Environment Malaysia (DOE) counted in, which are sulphur dioxide $(\mathrm{SO} 2)$, nitrogen dioxide $(\mathrm{NO} 2)$, carbon monoxide $(\mathrm{CO})$, and particulate matter with a diameter of 10 microns (PM10) and ground-level ozone (O3) [1]-[4]. Apart from ozone, air pollutant concentrations are normally higher in urban areas than in rural areas. In cities, air quality (particularly concerning PM10 and NO2 concentrations) tends to be worse near busy roads, where poorer communities often live [5]. 
Air pollution based on temporal variations previously had been studied by many researchers. Previous research proves the temporal variability is existed in the air pollutants [6]-[10]. Temperature and sunlight affect chemical reactions in the atmosphere that cause the concentration levels of air pollutants to be increased [7]. During hot weather, the air pollutants concentration is higher compared to during cold weather [6]. In the colder months $\mathrm{O} 3$ values at the monitoring site are lower and in the warmer months higher [8]. However, has stated that chemical and biophysical feedback are at high temperatures responsible for lower O3 concentrations [9]. PM10 concentrations rose sharply in the autumn for most stations and decreased during the winter in northern background and suburban stations [10].

This phenomenon also occurs in Malaysia. A study taken placed at Kuala Terengganu which analyzed hourly data from the Department of Environment (Malaysia) for the criteria pollutants (PM 10, CO, $\mathrm{O} 3, \mathrm{NO} 2$, and SO2) and meteorological factors (temperature, relative humidity, wind velocities) for 10 years found that the PM10, NO2, and SO2 concentrations during southwest monsoon (SWM) are higher [11]. CO also found significantly different based on the temporal variable. SWM recorded the highest average level of $\mathrm{CO}$, followed by inter-monsoons and northeast monsoon (NEM). This result also similar to [12]. However, according to [13], No major seasonal distinctions existed over the years between SO2, CO and NO2 concentrations, as calculated in Tukey's multiple comparison tests. In the coastal urban area, a different study found that $\mathrm{SO} 2$ and $\mathrm{NO} 2$ had a negative temperature correlation over the summer and monsoon seasons except post-monsoon seasons. Furthermore, during the whole season, except post-monsoon, the PM 10 showed a positive correlation with temperatures. Other than that, humidity showed a positive correlation with SO2 and a negative correlation with PM10 [14].

The concentration level of PM10 had become worse during the southwest monsoon. A study conducted at three testing sites in the highly populated industrial zones based on five years of observations between 2008 and 2012 found that PM10 has recorded the highest air pollution during southwest monsoon especially in industrial areas [15]. The highest concentration of air pollutants during the southwest monsoon is PM10 and its lower during the northeast monsoon [1]. A study on PM10 at two monitoring station Larkin and Pasir Gudang found that the average concentration of PM10 during southwest monsoon is the highest in both Larkin and Pasir Gudang [16].

In a study conducted by [1], O3 distributions were observed affected by monsoonal factor. During the winter monsoon from the northeast of the Malaysian Peninsula, the Indochina and the South China Sea has brought the pollutant $\mathrm{O} 3$ into a few urban areas in Malaysia affecting the highest concentration of O3 from January to Mac. Otherwise, O3 become lower from Julai to August [1].

The main objective of this research is to identify the temporal variation of air pollutants. Kelantan has recorded the highest reading of the air pollution index (API) at Kota Bharu city in 2019 [17]. Kelantan has been chosen as a study area in this study since the past study of air pollution in Kelantan is not focused on the temporal variations. However, there are studies about temporal variations in other states such as the study taken in Kuala Terengganu where analyzed the data of air pollutants and meteorological factors based on temporal variations which are southwest monsoon, northeast monsoon and inter-monsoon by [18]. In addition, meteorological factors in Terengganu are similar in Kelantan since these states are situated on the east coast of Malaysia. Stated by [19], Kelantan and Terengganu issued bad weather during mid-November caused by heavy rain.

\section{RESEARCH METHOD}

The first section describes the field of study included in the study. The second section details the data used for example the data type, and the data source and the data categories. In addition, the hierarchical agglomerative analyzes used is explained in detail in the third section.

\subsection{Study area}

The state of Kelantan lies at $6^{\circ} 7^{\prime} 38.8668^{\prime \prime}$ latitude and at $102^{\circ} 14^{\prime} 32.2332 "$ longitude on the northeastern corner of the peninsula. The illustrated area shows the whole area of Kelantan based on Figure 1. During the year Kelantan encounters hot and rainy weather with a total of about $2500 \mathrm{~mm}$ of rainfall per year since Malaysia lies close to the equator. The average temperature of Kelantan is $27^{\circ} \mathrm{C}$. The region of Kelantan, in particular, is encountered by two monsoon winds: The southwest monsoon between the end of May and September, and the north east monsoon between November and March [20]. In comparison with the southwest monsoon, the northeast monsoon causes more rainfall. The study selects Kota Bharu as an observation site. The town of Kota Bharu acts as the capital of Kelantan and the economy is growing rapidly. The map of Kota Bharu, Kelantan is shown in Figure 1. The area highlighted is the district of Kota Bharu. With an estimated 319,600 populations, the overall area of Kota Bharu is about $115.6 \mathrm{~km}^{2}$. 


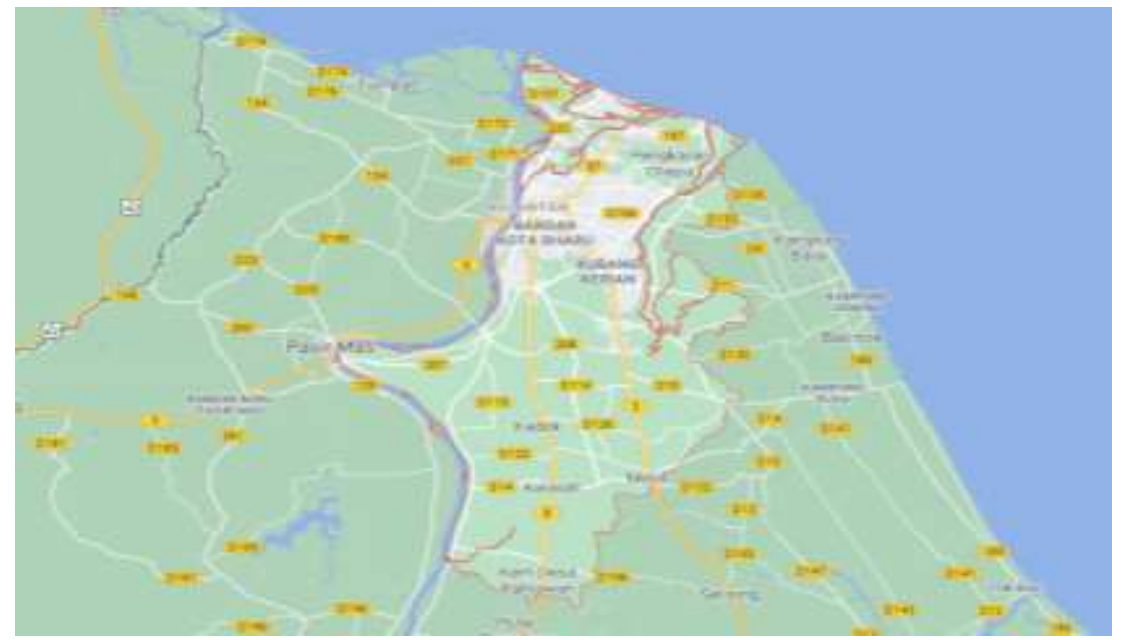

Figure 1. Map of Kota Bharu, Kelantan

\subsection{Data description}

This study used secondary data that has been collected by the Malaysian Department of Environment (DOE) through continuous air monitoring by Alam Sekitar Sdn Bhd (ASMA). Monthly data was collected at the air pollution monitoring station located in Tanjung Chat Secondary School Kota Bharu with $6.1465^{\circ}$ latitude and $102.2479^{\circ}$ longitude. This secondary data is quantitative. The dataset includes air pollutants concentration of $\mathrm{CO}(\mathrm{ppm}), \mathrm{NO} 2(\mathrm{ppm}), \mathrm{SO} 2(\mathrm{ppm}), \mathrm{O} 3(\mathrm{ppm})$ and $\mathrm{PM} 10(\mu \mathrm{g} / \mathrm{m} 3)$ are the variables for this study. It is recorded monthly from the year 2013 to 2017.

\subsection{Method of data analysis}

A hierarchical clustering method is utilised to cluster the monthly pollutant concentration. Boxplot comparison of clusters provided by hierarchical cluster analysis for each pollutant to indicates how the cluster is varied.

Hierarchical clustering analysis

Hierarchical clustering analysis is used to group the objects with similar characteristics into a few groups where each larger group contains a set of subgroups which are known as clusters. Two methods are commonly used in hierarchical clustering but, this research will utilize agglomerative clustering with the average group linkage method [21]. The formula to calculate this method is:

The equation of average linkage clustering as shown in (1):

$$
d_{12}=\frac{1}{k l} \sum_{i=1}^{k} \sum_{j=1}^{l} d\left(x_{i}, y_{j}\right)
$$

where:
$x_{1}, x_{2}, \ldots, x_{k}$
: Observation from cluster 1
$y_{1}, y_{2}, \ldots, y_{i}$
: Observation from cluster 2
$d_{(x, y)}$
: Distance between a subject with observation vector $\mathrm{x}$ and a subject with observation
vector $\mathrm{y}$

\section{RESULTS AND DISCUSSION}

This study analyzes the observation mean to get the cluster of monthly mean data for each pollutant. Table 1 shows the result for descriptive analysis. Based on the descriptive analysis of 52 observations, the minimum values for variables $\mathrm{SO} 2, \mathrm{NO} 2$ and $\mathrm{O} 3$ are the same which is $0.000 \mathrm{ppm}$. Meanwhile, the maximum values are all different where the maximum value for $\mathrm{SO} 2$ is $0.0046 \mathrm{ppm}, \mathrm{NO} 2$ with $0.0146 \mathrm{ppm}$ and for $\mathrm{O} 3$ is $0.0309 \mathrm{ppm}$. For $\mathrm{CO}$ and PM10 variables, the minimum values recorded are $0.4413 \mathrm{ppm}$ and $30.0968 \mu \mathrm{g} / \mathrm{m} 3$ respectively while the maximum values are $1.2513 \mathrm{ppm}$ and $90.8065 \mu \mathrm{g} / \mathrm{m} 3 \mathrm{respectively}$.

The mean value for the SO2 is $0.0009 \mathrm{ppm}$. The other four pollutants which are NO2, O3, CO and PM10 recorded mean values of $0.0106 \mathrm{ppm}, 0.0309 \mathrm{ppm}, 0.7354 \mathrm{ppm}$ and $53.8748 \mu \mathrm{g} / \mathrm{m} 3 \mathrm{respectively}$. Lastly, the standard deviation for SO2 is $0.0009 \mathrm{ppm}$ while NO2 with $0.0033 \mathrm{ppm}$ value of the standard deviation. As for the pollutant O3, the standard deviation read is $0.0104 \mathrm{ppm}$. Then, for CO and PM10, these 
two pollutants recorded the standard deviation of $0.1385 \mathrm{ppm}$ and $14.6630 \mu \mathrm{g} / \mathrm{m} 3$ respectively. Generally, the result on [11] has a bit lower average values on almost all pollutants compared to the current study although both studies situated in the region that experience the same monsoon season. According to [22], open coastal locations are often subjected to strong, even severe wind strengths. Meanwhile, [23] stated that a higher speed of wind could have caused decrease in pollutant concentration in a certain area. Therefore, the result [11] might happen because the study area located exactly on the coast which has a lower pollution concentration strongly affected by the wind speed compared to the location of the current study.

Table 1. Descriptive statistic

\begin{tabular}{lccccc}
\hline \multicolumn{1}{c}{ Variables } & $\mathrm{N}$ & $\begin{array}{c}\text { Minimum Value } \\
(\mathrm{ppm} \text { or } \mu \mathrm{g} / \mathrm{m} 3)\end{array}$ & $\begin{array}{c}\text { Maximum Value } \\
(\mathrm{ppm} \text { or } \mu \mathrm{g} / \mathrm{m} 3)\end{array}$ & $\begin{array}{c}\text { Mean } \\
(\mathrm{ppm} \text { or } \mu \mathrm{g} / \mathrm{m} 3)\end{array}$ & Standard Deviation \\
\hline Sulphur Dioxide & 52 & 0.0000 & 0.0046 & 0.0009 & 0.0009 \\
Nitrogen Dioxide & 52 & 0.0000 & 0.0146 & 0.0106 & 0.0033 \\
Ozone & 52 & 0.0000 & 0.0446 & 0.0309 & 0.0104 \\
Carbon Monoxide & 52 & 0.4413 & 1.2513 & 0.7354 & 0.1385 \\
Particulate Matter 10 & 52 & 30.0968 & 90.8065 & 53.8748 & 14.6630 \\
\hline
\end{tabular}

Figures 2 (a)-(e) is the cluster analysis using a dendogram based on monthly mean concentration for each pollutant. Further analysis on the distribution of pollutant according to the cluster is depicted in Figures 3 (a)-(e). Figure 2 shows the monthly clusters of sulphur dioxide (SO2). Based on vertical line on the dendrogram, three monthly clusters are appropriate for this air pollutant. Cluster one is clustered in January, February, August, August, October, November and December. Meanwhile, Cluster two comprises June and July and the last cluster consists of April and May. Based on Figure 3 (a), the increase in the mean of SO2 concentration from the first cluster until the third cluster is observed. Lowest concentrations are recorded in cluster one followed by cluster two and the highest mean recorded in cluster three. According to [24], lower temperature and humidity during rainy season (Cluster 1) leading to low-rate SO2 from the atmosphere. However, the box plot analysis could not confirm whether is there any definite significant differences between the cluster. It might be or not holding the result as found by [13], need for further analysis to confirm the differences.

The results in Figure 2 (b) show that NO2 is possible to divide into four clusters but only two clusters are explained. Cluster one consists of January, February, March, April and November. For cluster two consists of May, July, August, September and October. Meanwhile, only June in cluster three and December in cluster four. Furthermore, Figure 3(b) shows the distribution of NO2 concentrations according to four clusters. It can be observed that the NO2 concentrations for the three clusters are increasing from cluster one to cluster three. However, in the fourth cluster, the mean concentration of NO2 is declined as the lowest mean compared to the other three clusters. Therefore, the highest mean concentration of NO2 is recorded in cluster three where it occurs in June while the lowest mean concentration of NO2 is recorded in cluster four where it occurred in December. The increase of NO2 concentration in the earlier to the mid-year is due to the smaller number of rainy days during the southwest monsoon compared to the northeast monsoon period. As stated by [25] the amount of the air pollutant reduction by rainfall scavenging effect can be affected by the amount, duration and intensity of rainfall. The higher the amount, duration and intensity the rainfall scavenging effect will also high. This proven in the current study when NO2 concentration is high during the dry season (southwest monsoon) and lower during the rainy season (northeast monsoon).

Based on Figure 2 (c) above, shows that $\mathrm{O} 3$ clustering is possible to be divided into four clusters. The first cluster is comprised of October and November. The second cluster includes January, February, March, April, July and August. Concerning the third cluster, May and June are the months. The last cluster consists of one month which is December. During May and June, the highest monthly average concentrations of $\mathrm{O} 3$ are observed as indicated in Figure 3 (c). In [26] stated that, $\mathrm{O} 3$ is a product of vehicle emissions, energy plants, boiler factories, refineries, manufacturing installations, and other chemically-responding sources. O3 is the most likely to be harmful in urban areas during hot, sunny days, but in colder months it can reach higher concentrations as $\mathrm{O} 3$ can be transported long distances by wind. As the monitoring station in Kota Bharu, an urban area of Kelantan, it is possible to conclude that even during the northeast monsoon concentrations for $\mathrm{O} 3$ are slightly higher.

Dendrogram as in Figure 2 (d) is for PM10 concentration. It is depicting that three monthly clusters could be formed. For the first cluster, it clustered the months of January, February, March, April, May and September. Meanwhile, the months June, July and October grouped in cluster two. The last cluster consists of the months August, November and December. The concentration of PM10 of cluster one and two was nearly identical based on Figure 3 (d). PM10 concentration highest on cluster two during June, July \& October 
which coincided with the southwest monsoon. This event highly associated with high temperature and lower humidity during this dry season [14]. Otherwise, concentration is recorded at cluster three which may be represented as northeast monsoon.

For CO, three clusters can be observed from the dendrogram as in Figure 2 (e). The months in the first cluster are April, May, June, July, September and October. This monthly cluster could be representing the southwest monsoon period. Whereas, the northeast monsoon group represented by the third cluster (February, December \& January). Meanwhile the second cluster (March, November \& August) is an inter-monsoon group of clusters. Boxplot as shown in Figure 3 (e), a decreasing pattern is from the first cluster to the third cluster is detected. Therefore, the monsoonal effect on the concentration of $\mathrm{CO}$ is possible since there is a different concentration between southwest monsoon and northeast monsoon. According to [27], [28], incomplete combustion of fossil fuels and the combustion of biomass is the main sources of $\mathrm{CO}$. However, due to the considerable depositing phenomena during the northeast monsoon, hydroxyl groups function as sinks for removing CO from the atmosphere [28], [29].

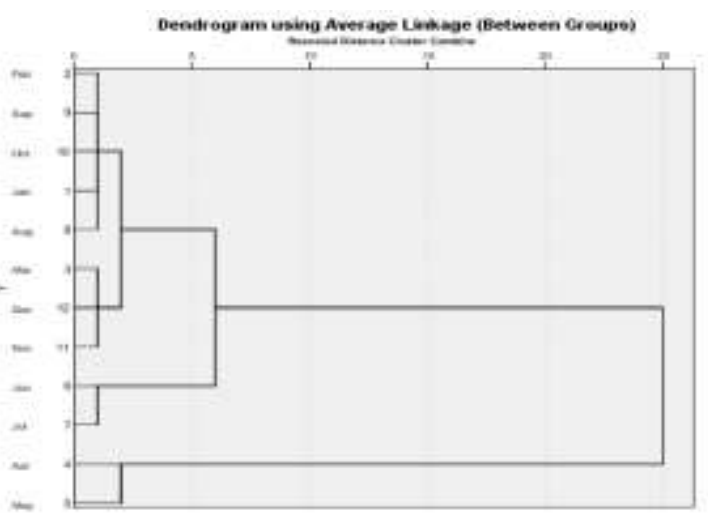

(a)

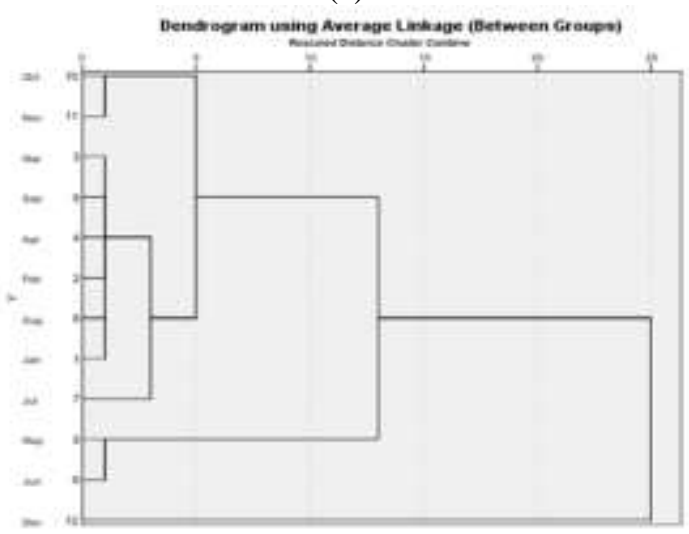

(c)

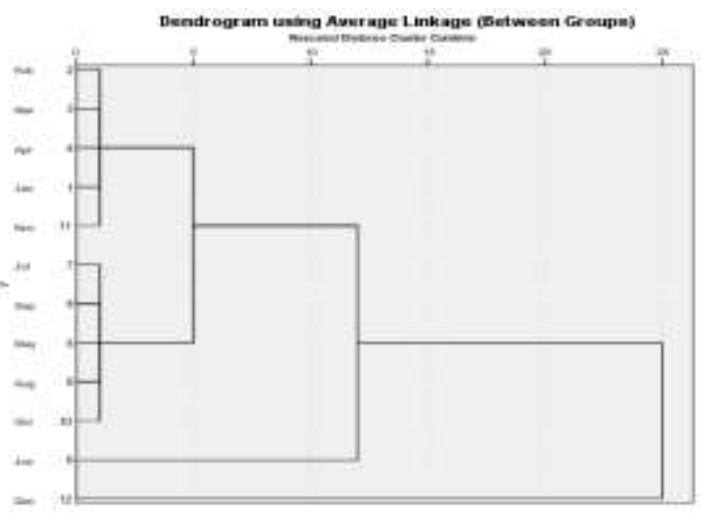

(b)

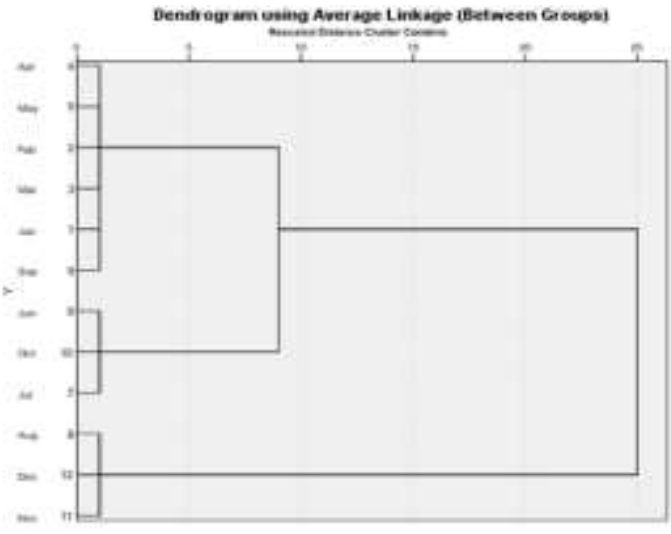

(d)

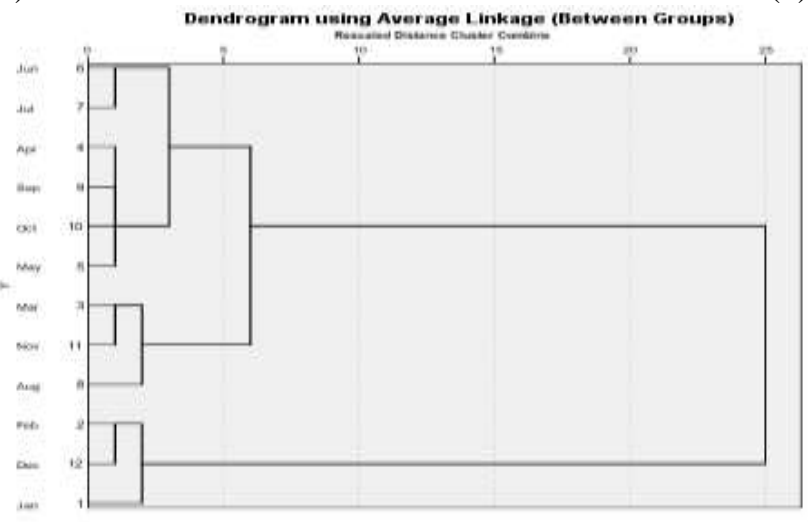

(e)

Figure 2. Monthly clustering; (a) $\mathrm{SO}_{2}$, (b) $\mathrm{NO}_{2}$, (c) $\mathrm{O}_{3}$, (d) PM10, and (e) $\mathrm{CO}$ 
So2

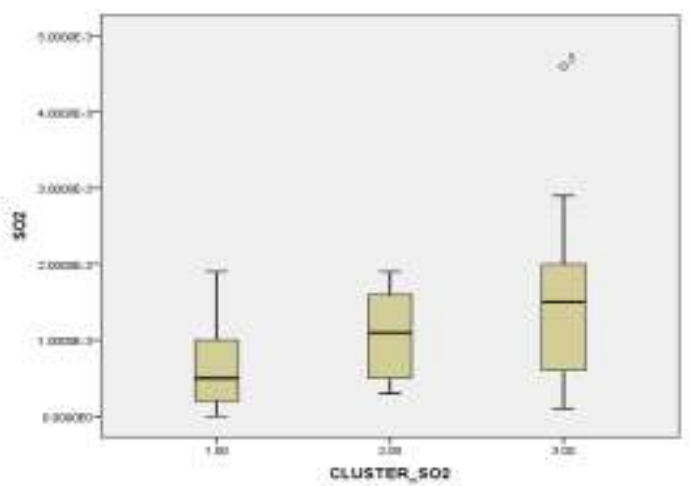

(a)

03

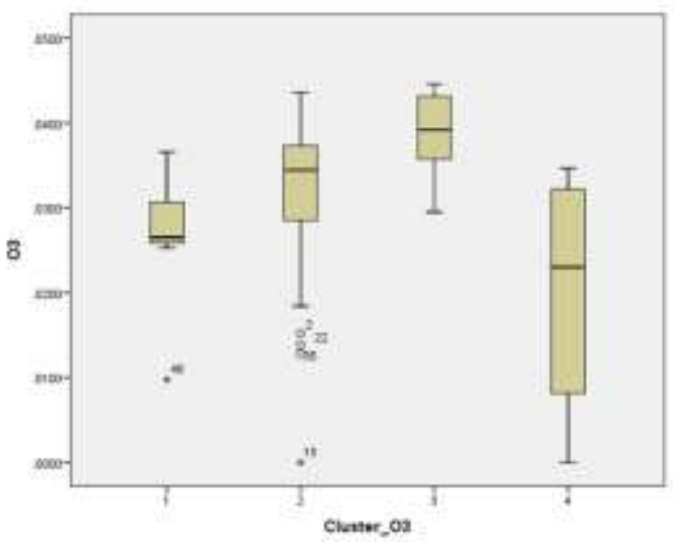

(c)
NO2

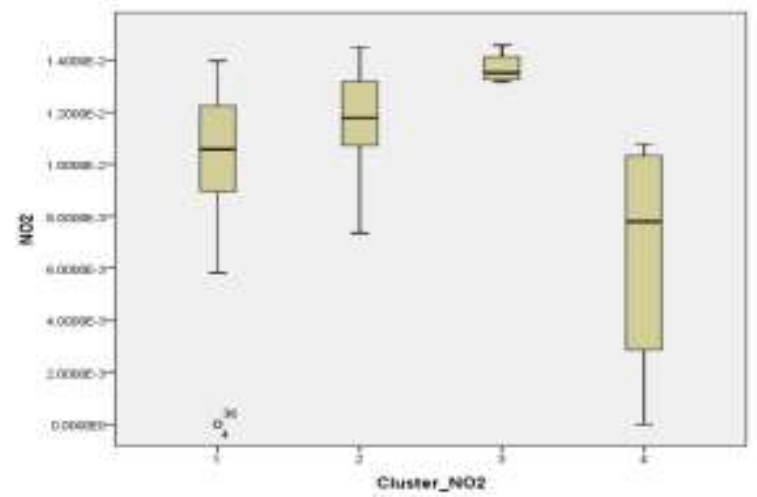

(b)

PM10

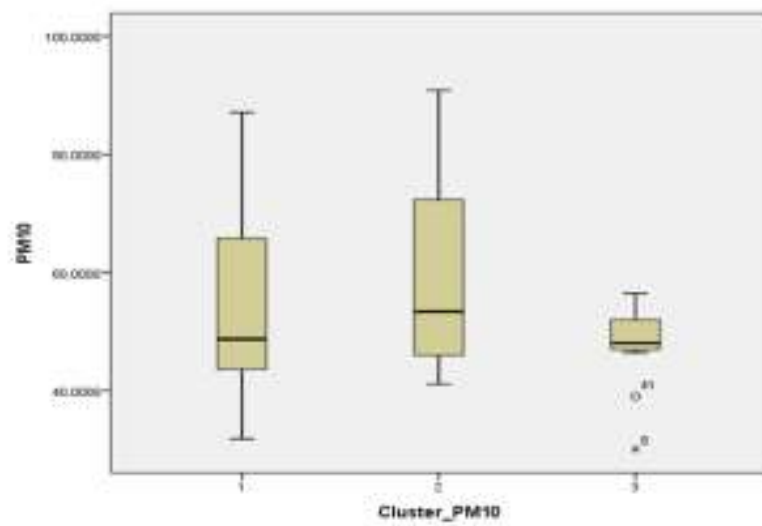

(d)

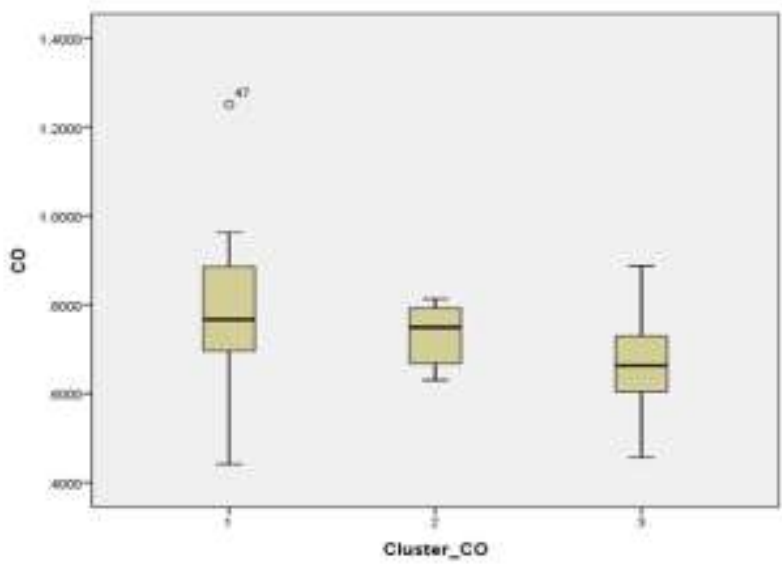

(e)

Figure 3. Boxplot based on cluster; (a) $\mathrm{SO}_{2}$, (b) $\mathrm{NO}_{2}$, (c) $\mathrm{O}_{3}$, (d) PM10, and (e) $\mathrm{CO}$

\section{CONCLUSION}

The result from this study shows that there is the existence of temporal variations of air pollutants. Generally, most of the cluster formed for each pollutant has a strong relationship to three seasonal monsoons which are southwest monsoon, northeast monsoon and inter-monsoon. From the monthly variation, it shows that the mean for SO2 concentration recorded the highest reading in months April and May which is during inter-monsoon as previously proven that there is a positive relationship between temperature and concentration in SO2. The highest mean concentration of NO2 was recorded during a high-temperature period which during SWM similar to what had been observed in previous study. The highest monthly 
average of $\mathrm{O} 3$ concentration recorded during May and June which is during the SWM. This paper also supports the previous study where the period of SWM is the period of the emissions from vehicles, power stations, factory boilers, refineries, manufacturing facilities and other sources that easily react chemically to the sun. The highest concentrations of PM10 can be seen during June to October which coincides with the southwest monsoon where it experiences a dry season all over the region in peninsular Malaysia. The concentration level of $\mathrm{CO}$ is the highest during the southwest monsoon. The above investigation of variations in $\mathrm{CO}, \mathrm{NO} 2, \mathrm{SO} 2, \mathrm{O} 3$ and PM10 concentrations in different monthly cluster in Kota Bharu, Kelantan shows that the mean of air pollution concentration in this large urbanized city depends on meteorological factors. One of the main factors that caused the high concentration is mainly related to the seasonal monsoon.

\section{ACKNOWLEDGEMENTS}

This paper and the research behind it would not have been possible without the exceptional support of Universiti Teknologi Mara Kota Bharu Campus for the facilities provided for the completion of the study. A thousand appreciation to the Department of Environmental Malaysia (DOE) for providing environmental data.

\section{REFERENCES}

[1] Mohtar, A. A. A., et al., "Variation of major air pollutants in different seasonal conditions in an urban environment in Malaysia," Geoscience Letters, vol. 5, no. 1, p. 21, 2018, doi: 10.1186/s40562-018-0122-y.

[2] Mabahwi, N. A., Leh, O. L. H., \& Omar, D., "Urban Air Quality and Human Health Effects in Selangor, Malaysia," Procedia - Social and Behavioral Sciences, vol. 170, 282-291, 2015, doi: 10.1016/j.sbspro.2015.01.038.

[3] Latif, M. T., et al., "The impact of urban growth on regional air quality surrounding the Langat River Basin, Malaysia," The Environmentalist, vol. 31, no. 3, pp. 315-324, 2011, doi: 10.1007/s10669-011-9340-y.

[4] Azmi, S. Z., Latif, M. T., Ismail, A. S., Juneng, L., \& Jemain, A. A., "Trend and status of air quality at three different monitoring stations in the Klang Valley, Malaysia," Air Quality, Atmosphere \& Health, vol. 3, no. 1, pp. 53-64, 2009, doi: 10.1007/s11869-009-0051-1.

[5] Department for Environment Food \& Rural Affairs. Public Health: Sources and Effects of PM2.5, 2020, https://laqm.defra.gov.uk/public-health/pm25.html

[6] Yousefian, F., Faridi, S., Azimi, F. et al., "Temporal variations of ambient air pollutants and meteorological influences on their concentrations in Tehran during 2012-2017," Sci Rep, vol. 10, no. 1, pp. 1-11, 2020, doi: 10.1038/s41598-019-56578-6.

[7] Jang E., Do W., Park G., Kim M. \& Yoo E. "Spatial and temporal variations of urban air pollutants and their concentrations in relation to meteorological conditions at four sites in Busan, South Korea," Atmos Pollut Res, vol. 8, no. 1, pp. 89-100, 2016, doi: 10.1016/j.apr.2016.07.009.

[8] Munir, S., T.M.H., A.M.F.M., E.M., A.H.A.A., A.R.S., \& I.H., “An Analysis into the Temporal Variations of Ground Level Ozone in the Arid Climate of Makkah applying k-means Algorithms," Thai Society of Higher Education Institutes on Environment, vol. 8, no, 1, pp. 53-60, 2015, doi: 10.14456/ea.2015.7.

[9] Steiner, A. L., Davis, A. J., Sillman, S., Owen, R. C., Michalak, A. M., \& Fiore, A. M., "Observed suppression of ozone formation at extremely high temperatures due to chemical and biophysical feedbacks," Proceedings of the National Academy of Sciences, vol. 107, no. 46, pp. 19685-19690, 2010, doi: 10.1073/pnas.1008336107.

[10] Chen, W., Yan, L., \& Zhao, H., "Seasonal Variations of Atmospheric Pollution and Air Quality in Beijing," Atmosphere, vol. 6, no. 11, pp. 1753-1770, 2015, doi: 10.3390/atmos6111753.

[11] Fong, S. Y., Marzuki Ismail \& Samsuri Abdullah., "Seasonal Variation of Criteria Pollutant in an Urban Coastal Environment: Kuala Terengganu," MATEC Web of Conferences, vol. 87, p. 03011, 2017, doi: 10.1051/matecconf/20178703011.

[12] Wong, Y.-K., Mohamed Noor, N., \& Mohamad Hashim, N. I., "Temporal Variation of Ambient PM10 Concentration within an Urban-Industrial Environment," E3S Web of Conferences, vol. 34, p. 02002, 2018, doi: $10.1051 / \mathrm{e} 3$ sconf/20183402002.

[13] Kayes, Imrul, Shahriar, Shihab A., Hasan, Kamrul, Akhter, Momotaj \& Kabir, Mohammad, Salam, Mohammed., "The relationships between meteorological parameters and air pollutants in an urban environment," Global Journal of Environmental Science and Management, vol. 5, pp. 265-278, 2019, doi: 10.22034/gjesm.2019.03.01.

[14] Jayamurugan, R., Kumaravel, B., Palanivelraja, S. and Chockalingam, M.P., "Influence of Temperature, Relative Humidity and Seasonal Variability on Ambient Air Quality in a Coastal Urban Area," International Journal of Atmospheric Sciences, 2013, pp. 1-7, doi: 10.1155/2013/264046.

[15] Mohd Zizi, N. A., Mohamed Noor, N., Izzah Mohamad Hashim, N., \& Yusuf, S. Y., "Spatial and Temporal Characteristics of Air Pollutants Concentrations in Industrial Area in Malaysia," IOP Conference Series: Materials Science and Engineering, vol. 374, p. 012094, 2018, doi: 10.1088/1757-899X/374/1/012094.

[16] Abdul Hamid, H., Hanafi Rahmat, M., \& Aisyah Sapani, S., "The classification of PM10 concentrations in Johor Based on Seasonal Monsoons," IOP Conference Series: Earth and Environmental Science, vol. 140, p. 012028, 2018, doi: 10.1088/1755-1315/140/1/012028.

[17] Abdullah, S. M. "Two stations in Kelantan record unhealthy API readings," NST Online, 2019, https://www.nst.com.my/news/nation/2019/09/523784/two-stations-kelantan-record-unhealthy-api-readings 
[18] Fong, S. Y., Marzuki Ismail \& Samsuri Abdullah, "Seasonal Variation of Criteria Pollutant in an Urban Coastal Environment: Kuala Terengganu," MATEC Web of Conferences, vol. 87, p. 03011, 2017, doi: 10.1051/matecconf/20178703011.

[19] Nazari, T. "MetMalaysia: Orange-Level Weather Warning for Kelantan And Terengganu Today," 2021, https://www.therakyatpost.com/2020/12/03/metmalaysia-orange-level-weather-warning-for-kelantan-andterengganu-today/

[20] Alias, N. E., Mohamad, H., Chin, W. Y., \& Yusop, Z. "Rainfall analysis of the Kelantan big yellow flood 2014," Jurnal Teknologi, vol. 78, pp. 9-4, 2016, doi: 10.11113/jt.v78.9701.

[21] Johnson, R. A., \& Wichern, D. W. "Applied multivariate statistical analysis," Upper Saddle River, NJ: Prentice hall, vol. 5, no. 8, 2002.

[22] Steyn, D. G. "Air pollution in coastal cities," In Air Pollution Modeling and its Application XI, Springer, Boston, MA, pp. 505-518, 1996, doi: 10.1007/978-1-4615-5841-5_53.

[23] Kim, K. H., Lee, S. B., Woo, D., \& Bae, G. N. "Influence of wind direction and speed on the transport of particlebound PAHs in a roadway environment," Atmospheric Pollution Research, vol. 6, no. 6, 1024-1034, 2015, doi: 10.1016/j.apr.2015.05.007.

[24] Bralić, M., Buljac, M., Periš, N., Buzuk, M., Dabić, P., \& Brinić, S. "Monthly and seasonal variations of NO2, SO2 and black-smoke located within the sport district in urban area, city of Split, Croatia," Croatica chemica acta, vol. 85, no. 2, pp. 139-145, 2012, doi: 10.5562/cca1966.

[25] Kim, S., Hong, K. H., Jun, H., Park, Y. J., Park, M., \& Sunwoo, Y., "Effect of precipitation on air pollutant concentration in Seoul, Korea," Asian Journal of Atmospheric Environment, vol. 8, no. 4, pp. 202-211, 2014, doi: 10.5572/ajae.2014.8.4.202.

[26] Ground-level Ozone Basics. US EPA. https://www.epa.gov/ground-level-ozone-pollution/ground-level-ozonebasics, 2021.

[27] K. Park and T. S. Rhee, "Source characterization of carbon monoxide and ozone over the Northwestern Pacific in summer 2012," Atmos. Environ, vol. 111, pp. 151-160, 2015, doi: 10.1016/j.atmosenv.2015.04.015.

[28] T. Holloway, H. Levy II, and P. Kasibhatla, "Global Distribution of CO. J. Geophy," Res. vol. 105, no. 10, pp. 123-147, 2000.

[29] J. M. Wallace and P. V. Hobbs, “Atmospheric Science: An Introductory Survey,” vol. 92, 2006. 